\title{
Site Dependence Earthquake Spectra Attenuation Modeling: Nigerian Case Study
}

\author{
Adekunle Abraham Adepelumi ${ }^{1}$, Tahir Abubakar Yakubu ${ }^{2}$, Olatunbosun Adedayo Alao ${ }^{1}$, \\ Akinsola Yusuf Adebayo ${ }^{1}$ \\ ${ }^{1}$ Department of Geology, Obafemi Awolowo University, Ile-Ife, Nigeria \\ ${ }^{2}$ Center for Geodesy and Geodynamics and Geodesy $(C G G)$, Toro, Nigeria \\ E-mail:adepelumi@gmail.com \\ Received June 23, 2011; revised August 7, 2011; accepted September 16, 2011
}

\begin{abstract}
Recent seismic events recorded in South-western Nigeria indicate that the country may not be aseismic as had hitherto thought. Geologic and geodetic evidences suggest the existence of large fracture zones (Romanche and Charcot) beneath the area. Considering the existence of these fracture zones, and the paucity of seismicity information, the development (oil exploration and production) taking place in offshore Nigeria in the last two decades and the ambitious planning for large future projects urgently call for the implementation of a comprehensive earthquake ground motion modelling which is a useful tool in site-dependent seismic hazard assessment in low to moderate seismicity region. In this study, ground-attenuation modelling based on stochastic approach was applied to predict the expected peak ground velocity and acceleration and spectral amplifications in two geologic settings. The seismic ground motion has been modelled using the September 11, 2009 earthquake of magnitude $4.8(\mathrm{Mw})$ as case study. Synthetic seismic waveforms from which parameters for engineering building design could be obtain have been derived. From the seismograms computed, the seismic hazard for south-western Nigeria, expressed in terms of peak ground acceleration and peak ground velocity have been estimated. The peak ground acceleration estimated for the study area ranges from 0.16 to $0.69 \mathrm{~g}$, and the peak ground velocity from 18.0 to $58.3 \mathrm{~m} / \mathrm{sec}$. The high peak values of accelerations and amplifications delineated are possibly due to the presence of the low velocity layers. In general, a good correlation between the synthetic and field data was observed. These results attest to the efficacy of the modelling exercise, and assessment of the seismic risk that the region would likely be subjected to. Also, the earthquake engineering design parameters derived may be used to derive new civil engineering building codes for the affected area.
\end{abstract}

Keywords: Ground-Motion, Modelling, Seismic, Fracture, Velocity, Acceleration

\section{Introduction}

Nigeria is supposedly said to be a region of low to moderate seismicity but there has been course in the recent to investigate the seismicity of Nigeria to be able to forecast future occurrence of earthquake for engineering foundation purposes. Earthquake all over the world are known to always occur in regions of high seismicity along tectonic plate boundaries, and are known as interplate earthquakes, whilst earthquakes worldwide predominantly occur along tectonic plate boundaries (interplate regions). Destructive earthquakes do occur away from the plate margins and are known as intraplate earth- quakes. The earthquake felt in Abeokuta on $11^{\text {th }}$ September 2009 at by 03:10:30 am has a moment magnitude of 4.8, and Intensity of 7. It was felt by the residents of the area. The occurrence intraplate earthquakes in Nigeria is seen to be characterized by the so called "high stress drop" which has been interpreted recently as the result of high velocity fault-slip in the generation of seismic waves at the source of the earthquake [1]. High slip velocity is considered to be partly attributed to the thrust faulting mechanisms typifying intraplate earthquakes.

The usual occurrences of these intraplate events appears random in both space and time and are often associated with significant damage due to the vulnerability of 
building stocks. These events in the case of Nigerian can be classified as tremors and aftershocks of far and near distant earthquakes. [2] used the peak ground acceleration (PGA) or peak ground velocity (PGV) to scale the spectrum to reflect the seismicity of site. His methodology was adopted in this study. The model adopted has been used in other part of the world that has experienced interplate earthquakes like California and its application in a region of assumed low seismicity is assumed conservative.

The response spectrum model which includes Newmark and Hall model assumes a unique normalized response spectrum for rock sites, which implies that the spectral property of an earthquake depends solely on site conditions and not on the earthquake source and path only. In contrast, a uniform hazard spectrum displays significant regional variations in shape of the response spectra that are generated across the Nigeria plate. The uniform hazard spectrum will possess a higher frequency in the sedimentary regions than the metasediment regions. These differences in frequency observed in the response spectra of this region is believed to be results of the different wave transmission in the bedrock and the different stress associated with the different faulting mechanism. However, the relative importance of such of these factors is still under investigation.

The derivation of a regional response spectrum from first principles requires the analysis of a large number of strong motion accelerograms representatives of the whole range of source, path and site conditions. In aseismic region such as Nigeria, Six (6) accelerograms recorded recently were used to undertake the empirical numerical modelling carried out in this study.

The thrust of this paper is to model synthetic earthquake seismograms that will be generated by an earthquake having a magnitude greater than 4.5 and above on the Richter scale; model the effect of various seismic parameters on ground motions caused by this earthquake using available seismological model; employ the stochastic techniques for the numerical modelling; develop a site specific design response spectra for Nigeria that will be used in earthquake engineering studies for dynamic analyses (structural dynamic and structural engineering) which may take the form of response spectral analyses (RSA) or time-history analyses (THA). Compare the response spectra derived from the synthetic seismograms with those derived from the seismic event that was recorded in three locations in Nigeria (Ile-Ife, Kaduna and Nsukka) on $11^{\text {th }}$ September 2009. Finally, an attempt will be made to assess the seismic hazard of these areas.

\section{Geology of the Area}

The principal investigated area covers Ile-Ife (basement terrain) and Abeokuta (sedimentary terrain) both located in South-western Nigeria. The former falls within the Dahomey basin while the later fall within the basement complex region. The surface geology of Abeokuta is made up of the both the Ilaro Formation and the Recent littoral alluvial to Coastal Plain sand deposits (Benin Formation). The Ilaro Formation is best described by the sandy strata between $22 \mathrm{~m}$ and $72 \mathrm{~m}$ penetrated by the Ota borehole (GSN. BH. 927). The total thickness of the type section is about $46 \mathrm{~m}$. The Ilaro Formation consists of rather massive sandstone with local clay intercalations (Figure 1). The Ilaro Formation is fine to medium grained, and is fairly well sorted. The The Ilaro Formation lies conformably on the Oshoshun Formation (Lower -Middle Eocene) and locally unconformably beneath the Benin Formation (Oligocene-Pleistocene). The Ilaro Formation is mostly likely to be Middle to Upper Eocene in age [3].

In the study area the thickness of the Benin Formation is between 60 to $80 \mathrm{~m}$. The Benin Formation consists of continental sands with shale intercalations usually with good groundwater potential. The Ilaro Formation is estimated to be about $70 \mathrm{~m}$ thick and shows rapid lateral facies changes. This can affect the aquifer quality of the Ilaro Formation [4]. However, the underlying Ewekoro Formation is known to have good groundwater aquifer (limestone).

Entire Ile-Ife and environs area is located within the Ife-Ilesha schist belt, which is predominantly a migmatite gneiss-quartzite complex. [5] classified the rocks of the Ife-Ilesha schist belt into the migmatite gneissquartzite complex as slightly migmatized to non-migmatized meta-sedimentary and meta-igneous rocks, and members of the older granite suite. The geology at the campus is shown in Figure 1. The gray gneiss occurs in the pediment area and is the oldest recognizable rock within the migmatite-gneiss-quartzite complex. This unit displays augen structures in some places. The slightly migmatized to non-migmatized meta-sedimentary and meta-igneous rocks of the campus belong lithologically to mafic-ultramafic rocks. They occur in the southern and eastern parts of the town. A dolerite dyke cuts across the granite gneiss on hill 2 in the north-central part. Minor veins and pegmatites of various lengths and thicknesses cut across the country rock in both a concordant and a discordant manner. Two prominent NE-trending thrust faults (F1 and F2) occur in the northern and south-central parts of the campus, respectively. Locally, the rocks types found in Ile-Ife area is underlain overlain by a relatively thick covering of weathered materials made up of a sequence of lateritic clay (aquitards), clayey sand/sand, and weathered/fractured bedrock. 


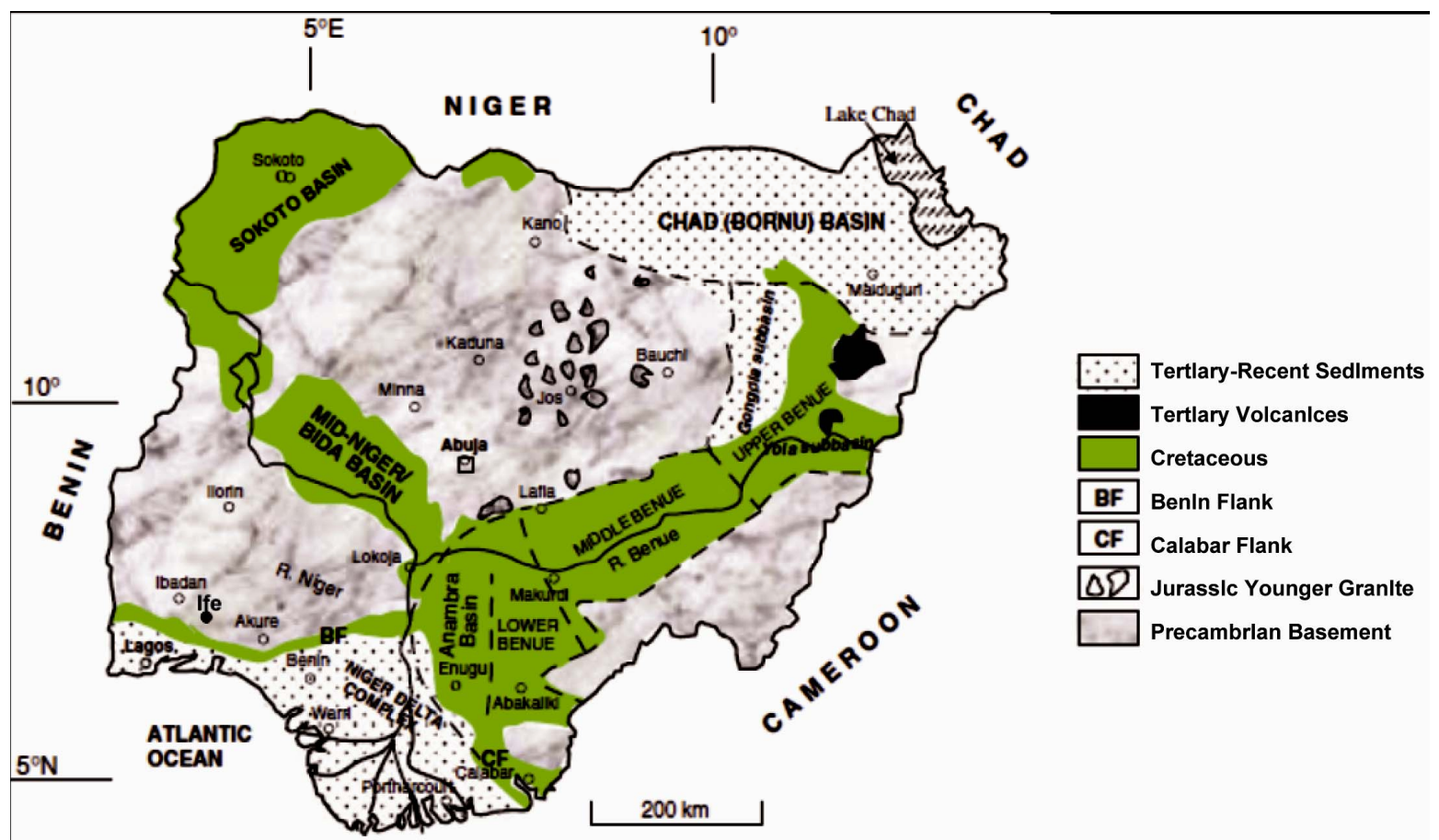

Figure 1. Geologic map of Nigeria (modified after obaje, 2009).

\section{Methodology}

The investigated area, South-western Nigeria is located on a stable part of the Laurasian plate, and is in a region of low seismicity. There has been no history of a major earthquake occurrence in this region, but it has a several potential sources of earthquake e.g. the Romanche and Charcot fracture zones where future ground movement may occur. The only history of earth movement (tremor) in South-western Nigeria is that that occurred in IjebuOde on July 28, 1984. Also, very recently, an earthmovement (tremor) of moment magnitude 4.8 and intensity of seven (7) occurred on the $11^{\text {th }}$ of September 2009 at about 03:11 am (GMT). It was highly felt by the residents of Abeokuta and environs. This section treats an overview of the ground modelling methods used in this study. There are two main methods commonly used for the generation of earthquake accelerograms. They are: Deterministic methods and stochastic methods. However, for this study, the stochastic method was adopted based on the perceived robustness of the method.

For example, [6] performed a site effect seismic modelling of the Tolmezzo-Ambiesta dam in North-eastern Italy. They show that their numerical modelling output compared favourably with the field results. Also, [7] used an iterative Gauss-Newton to model and invert the nonlinear problem displacement spectra of earthquakes recorded by the French accelerometric network at regional scale as the product of source, propagation (in- cluding geometric and anelastic attenuation), and site effects. A very robust site responses relative to an average rock-site response was derived, allowing them to identify good reference rock sites. [8] performed a numerical modelling of the attenuation of peak ground velocity for intraplate earthquakes in Australia using the CAM stochastic modelling approach. They obtained a good agreement between both historical intensity data and instrumental earthquake data with CAM model result. [9] carried out a Stochastic simulations of the seismological model for the magnitude 9.3 Aceh earthquake (Indonesia) on the $26^{\text {th }}$ of December in 2004, were performed and compared with the response spectra recorded on a rock site in Singapore. They further the attenuation behaviour of earthquake ground shaking into three 1) regional factors, 2) local factors, and iii) site factors.

In-addition, [10] used small-to-moderate earthquakes located within $200 \mathrm{~km}$ of San Francisco to characterize the scaling of the ground motions for frequencies ranging between 0.25 and $20 \mathrm{~Hz}$. They obtained results for geometric spreading, $\mathrm{Q}(f)$, and site parameters. The results of their analysis showed that, throughout the Bay Area, the average regional attenuation of the ground motion can be modeled with a bilinear geometric spreading function with a $30-\mathrm{km}$ crossover distance, coupled to an anelastic function. Furthermore, [11] carried out a holistic ground-motion modeling techniques for use in Global Shake Map in different tectonic settings of the world. [12] showed that ground-motion prediction is still affected by 
large, and only slowly decreasing, uncertainties even for well-instrumented areas with long histories of strongmotion observation (e.g. California). Also, [13] summarised the importance of predicting the expected earthquake ground motions at sites of interest in Engineering seismology. He concluded that an important consideration when selecting the modelling parameters is the possible dependence of ground motions on geographical region. [14] characterised and model the seismic response at liquefied sites and a liquefiable site in China using the JBF seismic attenuation model. They concluded that for the two selected sites, the seismic response spectra estimated from strong motion attenuation model are the same.

\section{Stochastic Methods}

The generation of intraplate earthquake accelerograms must consider random variabilities which can be accounted for using stochastic methods. With the inventions of computers and fast Fourier algorithms; the stochastic methods which are basically dependent on frequency domain analysis is less cumbersome and faster for use to generate synthetic accelerograms of [15]. The stochastic procedure typically consists of a deterministic Target Fourier amplitude spectrum defining the frequency content and a set of random phase angle defining the phase arrivals. An amplitude function is used to modulate the accelerograms to a realistic duration. Kanai-Tajimi filter has developed within a stochastic frame work to generate artificial accelerograms. More elaborate Fourier spectrum models have been developed by [16] and [17] using earthquake magnitude, source distance and site classification as the controlling parameters. [18] proposed a procedure which is a hybrid of stochastic and deterministic methods. Furthermore, [19] applied the stochastic technique to derive a tentative set of updated hybrid empirical hard-rock ground motion estimates for PGA, PGV and 5\% damped linear elastic response spectra for eastern North America. [20] successfully applied this method in the West Coast of North America.. Also, he was able to show that this method offers an alternative, more empirically based, method for predicting nearsource ground motions from large-magnitude earthquakes in ENA and other stable continental regions.

GENQKE software version 1.0 was used for the numerical computation. This software was used in deriving the Fourier spectrum from a target response spectrum. Synthetic accelerograms was generated to match code response spectra using such a program. Whilst code designed response spectra are typically smoothed and based on implicit assumptions, empirical response spectrum models addressing specific source, path and site condi- tions and are more transparent. Also, a seismological model originally developed by [21] and subsequently modified by [22-24] identifies the important factors affecting the properties of the earthquake ground motion and distils these factors into few key parameters. The advantage of this model is its generic, simple to use, and its suitability for the modelling of seismic hazard in areas of low seismicity areas where details of potential earthquake sources are generally unknown. The Fourier spectrum specified in the model is expressed as the product of a source factor, a geometrical attenuation factor, a whole path attenuation factor and factors representing effects near the surface. Interestingly, the source factor has been found to be consistent with Fourier transform of the shear waves predicted by point shear dislocation theory [25]. Ground motion parameters can be obtained from the specified Fourier amplitude spectrum either using random vibration theory according to [24] or by generating synthetic accelerograms as described in chapter four. Such parameters predicted by model generally provide a good match with field observation, particularly following recent modifications to the original source function by [26]. Also, [27] showed that the seismological model produces results which are comparable to the previously described deterministic ray-theory method.

\section{The Seismological Model}

\subsection{Overview}

In the seismological model, the Fourier amplitude spectrum of displacement $\mathrm{A}(f)$ of seismic waves reaching the exposed surfaces of bedrock may be expressed as the product of a number of factor:

$$
\mathrm{A}(f)=\mathrm{C} \times \mathrm{M}_{\mathrm{o}} \times \mathrm{S}(f) \times \mathrm{G} \times \mathrm{A}_{\mathrm{n}}(f) \times \mathrm{V}(f) \times \mathrm{P}(f)
$$

where

$\mathrm{C}$ is a scaling factor.

$\mathrm{M}_{\mathrm{o}}$ is the seismic moment $\mathrm{S}(f)$ is the regional source spectrum.

$\mathrm{G}$ is the regional geometric attenuation factor.

$\mathrm{A}_{\mathrm{n}}(f)$ is the regional anelastic whole path attenuation.

$\mathrm{V}(f)$ is the local upper crust amplification filter.

$\mathrm{P}(f)$ is the local upper crust attenuation filter

\subsection{Regional Source Factor $S(f)$ and Mid Crust Factor $\left(\gamma_{\mathrm{mc}}\right)$}

Regional and generic, source factors have been used to generalize the average behaviour of seismic waves or energy generated at the source of the earthquake to the whole region. Countries like Nigeria which has not captured sufficient near-field strong motion data to develop 
conventional (empirical) attenuation models of its own have the option to adopt the alternative approach of undertaking stochastic simulations of the seismological model which is characterized by the separation of the ground motion model into the "source", "regional" (path) and "local" components(the "local" component is not to be confused with the "site" components which deal with the effects of the surface sediments of the site). The heuristic framework of resolving ground shaking into the "source", "path" and "local" components enables telemetry data recorded by seismometers from long distances to be corrected for the path (and local) effects and hence enable seismic waves radiated from the "source" of the earthquake to be back-calculated. The stochastic seismological methodology was pioneered in the lowmoderate seismicity regions of Central and Eastern North America (CENA) where strong motion data was lacking but sufficient telemetry data from the Eastern Canadian Telemetry Network (ECTN) was available to construct viable seismological models for the region, for example, [25,28,29].

In this case study, the generic source factor of intraplate earthquakes as developed by [25] was used to represent the geological condition in our study area in Nigeria since they share similar features. Equations (2) to (8) gives the generic source factor $\mathrm{S}(f)$ for displacement amplitude defining the Fourier spectrum of the seismic shear energy generated at the source of earthquake:

$$
\mathrm{S}(f)=\mathrm{CM}_{\mathrm{o}}\left[(1-\mathrm{v}) \mathrm{S}_{\mathrm{A}}+\in \mathrm{S}_{\mathrm{B}}\right]
$$

where

$$
\begin{gathered}
\mathrm{S}_{\mathrm{A}}=1 /\left[1+\left(f \mid f_{\mathrm{A}}\right)^{2}\right] \\
\mathrm{S}_{\mathrm{B}}=1 /\left[1+\left(f / f_{\mathrm{B}}\right)^{2}\right] \\
\mathrm{C}=\mathrm{R}_{\mathrm{p}} \mathrm{FV} / 4 \pi \rho \beta^{3}
\end{gathered}
$$

$M_{o}$ is the seismic moment, $R_{p}$ is the wave radiation factor, $\mathrm{F}$ is the free surface amplification factor, $\mathrm{V}$ is the factor partitioning seismic energy in the two orthogonal directions. (the product of $\mathrm{R}_{\mathrm{p}} \mathrm{FV}$ is 0.78 ), is the density of the rock at depth of rupture is the shear wave velocity (SWV) of the rock at the depth of rupture. The intraplate source model was based on the generic hard rock conditions obtained from a global database with $=2.8 \mathrm{t} / \mathrm{m}^{3}$ and $=3.8 \mathrm{~km} / \mathrm{s}$ at a depth approximately $12 \mathrm{~km}$.

The magnitude-dependent corner frequencies $f_{\mathrm{A}}, f_{\mathrm{B}}$ and the proportioning factor $\mathrm{V}$ are listed as follows:

$$
\begin{aligned}
& \log f_{\mathrm{A}}=2.41-0.533 \mathrm{M} \\
& \log f_{\mathrm{B}}=1.43-0.188 \mathrm{M} \\
& \log \epsilon=2.52-0.637 \mathrm{M}
\end{aligned}
$$

where $\mathrm{M}$ is the moment magnitude which has also been denoted as $\mathrm{M}_{\mathrm{w}}$, the amplitude of S-wave generated from the source of the earthquake is inversely proportional to the shear wave velocity of the surrounding crust raised to a power of 3, according to (5) above. Adjust to allow for other parameter values can be made through the midcrust modification factor defined as:

$$
\gamma_{\mathrm{mc}}=\left(\frac{3.8}{V_{S, 8}}\right)^{3}\left(\frac{2.8}{\rho_{8}}\right)
$$

where $V_{S, 8}$ and $\rho_{8}$ is the crustal shear wave velocity is the shear wave velocity and density respectively at 8 km depth.

\subsection{Regional Geometrical Attenuation Factor}

The geometrical $\mathrm{G}$ factor represent the attenuation of the amplitude of the radiated seismic waves resulting purely from the geometrical spread of energy as opposed to dissipation of energy. The $\mathrm{G}$ factor in the near-field conforms to spherical attenuation and is independent of regional conditions. The $\mathrm{G}$ factor becomes regionally dependent in the far-field where the attenuation pattern is influenced significantly by seismic waves reflected from the Mohorovicic discontinuity which defines the interface between the earth crust and the underlying lithosphere. The significance of the Mohorovicic discontinuity reflection increases with decreasing thickness of the earth crust, according to

$$
\begin{gathered}
G(R, D)=\frac{30}{R}(\text { for } R \leq 1.5 D) \\
G(R, D)=\frac{30}{1.5 D}(\text { for } 1.5 D \leq R \leq 2.5 D) \\
G(R, D)=\frac{30}{1.5 D} \sqrt{\frac{2.5 D}{R}}(\text { for } R \leq 2.5 D)
\end{gathered}
$$

where $\mathrm{R}$ is the source-site distance of the earthquake and is crustal thickness.

\subsection{Regional Whole Path Attenuation Factor $A_{n}(f)$}

Whole path attenuation is particularly important in the modeling of ground motions from long-distant earthquake. Large-magnitude earthquakes generated at sourcesite distance( $\mathrm{R})$ exceeding $100 \mathrm{~km}$ are typified by lowfrequency(long-period) seismic waves, since the high frequency components have greatly diminished in amplitude as a result of energy absorption along the sourcesite wave travel path. The attenuation mechanism may be characterized by the value of seismological quality factor $\mathrm{Q}$ (equivalent to $\mathrm{Q}_{\mathrm{o}}$, namely $\mathrm{Q}$ at frequency of $1 \mathrm{~Hz}$ ) as obtained from seismological monitoring in the region. The value of $\mathrm{Q}$ may be substituted to develop the filter function $\mathrm{A}_{\mathrm{n}}(f)$ representing the effects of whole path at- 
tenuation of seismic waves propagating within the earth's crust:

$$
\mathrm{A}_{\mathrm{n}}(f)=\mathrm{e}^{-\frac{\pi \cdot f \cdot \mathrm{R}}{\mathrm{Q}(f) \mathrm{V}_{S}}}
$$

where $f$ is the wave frequency, $\mathrm{R}$ is the length of the wave travel path and $V_{s}$ is the shear wave velocity. The $\mathrm{Q}(f)$ is then defined by:

$$
\mathrm{Q}(f)=\mathrm{Q}_{\mathrm{o}} f^{\mathrm{n}}
$$

Substitution of (14) into (13) yields the estimated whole path attenuation factor. An empirical correlation between $\mathrm{Q}_{\mathrm{o}}$ and $\mathrm{V}_{\mathrm{uc}}$ has been developed, employing information obtained from global sources in conjunction with that from local studies:

$$
\mathrm{Q}_{\mathrm{o}}=100+2.5 \mathrm{~V}_{\mathrm{uc}}^{4.5}\left[\mathrm{~V}_{\mathrm{uc}} \geq 1.6 \mathrm{~km} / \mathrm{s}\right]
$$

Further, an empirical correlation between $\eta$ and $\mathrm{Q}_{\mathrm{o}}$ based on global database has been developed:

$$
\eta=0.0000008 \mathrm{Q}_{\mathrm{o}}^{2}-0.0014 \mathrm{Q}_{\mathrm{o}}+0.93
$$

\subsection{Local upper Crustal Amplification Factor $\mathrm{V}(f)$}

Upwardly propagating shear waves are amplified when the waves cross from one medium to a lower velocity medium and can be explained by principle of conservation of energy. Upper-crust amplification is a function of the shear wave velocity profile (its value and gradient) in the earth crust, particularly at shallow depths and is period or frequency dependent. The extent of upper-crust amplification may be predicted from [17], using and to represent the rock density and SWV at the source depth, which is typically assumed as $\mathrm{z}=\mathrm{D}=8 \mathrm{~km}$ and at a depth corresponding to period of interest.

$$
\mathrm{V}\left(\mathrm{V}_{\mathrm{S}}, \rho\right)=\sqrt{\frac{\rho_{\mathrm{B}} \mathrm{V}_{\mathrm{B}}}{\rho_{\mathrm{A}} \mathrm{V}_{\mathrm{A}}}}
$$

To relate the period of interest to rock depth, the quarter-wavelength approximation method is required. This method allows the values of velocity $(\mathrm{V})$ to be averaged to a depth equivalent to the quarter-wavelength of the upwardly propagating shear wave, for applying [17].

\subsection{Local upper Crust Attenuation Factor $P(f)$}

Wave transmission quality within bedrock is not uniform with depth. Attenuation in the upper crust is a local phenomenon and is represented by a local factor and the mechanism occurs over a short transmission distance, as for attenuation in soft sediments. The upper crustal attenuation factor $\mathrm{P}(f)$ in the seismological model has been defined by (18)

$$
\mathrm{P}(f)=\mathrm{e}^{-\pi f \kappa}
$$

Where $\kappa$ is measured from the Fourier transform of seismic waves recorded from the very near-field. The parameter $\kappa$ is generally difficult to measure in regions of low and moderate seismicity because of magnitude or epicentral distance requirement associated with the measurements. A method for estimating $\kappa$ is to make inferences from the shear wave velocity near to rock surface. Empirical correlation of $\kappa$ with the average shear-swave velocity of the upper crust $\mathrm{V}_{\mathrm{uc}}$ (taken as the upper $4 \mathrm{~km}$ depth), as well as at $30 \mathrm{~km}$ depth, have been developed based on global sources:

$$
\begin{gathered}
\kappa=0.145-0.12 \ln \left(\mathrm{V}_{\mathrm{uc}}\right) \geq 0\left[\mathrm{~V}_{\mathrm{uc}} \geq 1.6 \mathrm{~km} / \mathrm{s}\right] \\
\kappa=\frac{0.057}{\mathrm{~V}_{\mathrm{S}}, 0.03^{0.8}}-0.02\left[0.5 \mathrm{~km} / \mathrm{s} \leq \mathrm{V}_{\mathrm{S}}, 0.03\right]
\end{gathered}
$$

\subsection{Soil Site Response Function $F(f)$}

Experiences gathered from previous earthquake has repeatedly shown that the intensity of damage produced from ground shaking motions, are strongly influenced by local site conditions, in particular the influence of relatively shallow geologic material on nearly vertically propagating body waves as soils behave nonlinearly when subjected to strong levels of ground shaking, it is more appropriate to account separately for site effects from bedrock and soil layers, and hence a site response transfer function $\mathrm{F}(f)$ can be added to (1). It is worth mentioning that soil site response function $\mathrm{F}(f)$ is not single value for specific site, as it depends on the level of soil damping and is, in turn, related to the shaking level. Together with different resonant conditions, which are interactive effects arising between the earthquake scenario and site condition, the soil site response factor would vary for different earthquake events. That represents a unique and distinctive feature of using the combination of seismological model and site response function as the attenuation model. For this study, a new Matlab script was written for the stochastic modelling, while the earthquake events recorded in September 2009 was used for the numerical modelling and computations.

\section{Results and Discussion}

The result obtained from the seismological computation and modeling has shown that ground motion modelling is a useful tool in site-dependent seismic hazard assessment in low to moderate seismicity region. It helps in giving ideas on the type of earthquake signature to be 
expected in various geologic settings. In this study, ground-attenuation modelling based on ground motions stimulated stochastically in accordance with seismological model was carried out over two geological settings: sedimentary terrain and the basement complex. The results obtained were compared in order to determine the efficacy of the modelling exercise carried out. Ground motion modelling has to be taken into consideration in Nigeria especially the Southwestern region in order to address seismic risks, and develop effective mitigation measures in view of its high population density, recent development and concentration of commercial activities and local engineering practices that have not embraced aseismic design principles.

\subsection{Seismological Parameter Used}

The mean focal depth or depth to the epicentre is taken as $\mathrm{h}=20 \mathrm{~km}$ in the seismological modelling. With this depth range, it is considered that $\rho=2.8 \mathrm{t} / \mathrm{m}^{3}$ and $\beta=3.7$ $\mathrm{km} / \mathrm{s}$, which is consistent with values obtained from [30]. The mid-crust modification factor is accordingly equal to 1.0 - 1.1. The data from [30] gave value of $\mathrm{D}$ for Nigeria to be $30 \mathrm{~km}$. The quality factor $\mathrm{Q}_{\mathrm{o}}=121$ and the upper crustal attenuation factor $\kappa=0.02$ have been obtained from the regional shear wave velocity parameter (of the upper $4 \mathrm{~km}$ depth).

To develop representative local factors representing the 2 mechanisms, the shear-wave velocity profile of the crustal rock has been designed based on [30] and the methodology of constructing rock SWV profiles.

\subsection{Comparism of Simulated with Instrumented Recorded Data}

Synthetic accelerogram have stimulated stochastically using computer program GENQKE. The response spectra calculated from six (6) accelerograms with random phase angles are averaged for different earthquake scenarios. The average response spectra computed are shown in Figures 2-4. The response spectra recorded on a rock site in Ile-Ife and Abeokuta area have been plotted on same graph for direct comparison.

It is worth-mentioning that the earth tremor of $11^{\text {th }}$ September 25, 2009 was also recorded at Nsukka and Kaduna respectively. For comparison sake, we would briefly compare the earthquake field data obtained at these locations also with our model results. The model results shown in Figures 2-4 correlate reasonably well with the recorded three components tremor data at three major locations in Nigeria at Ile-Ife, Nsukka and Kaduna (See Figure 5). From this figures, it is evident that the model result is comparable in magnitude to the event recorded at Ile-Ife; this offered the opportunity to test the robustness of the stochastic model. The site-source distance of this second event from Kaduna was only about $588 \mathrm{~km}$ (which is 0.6 times the site-source distance of the Abeokuta earthquake).The recorded model comparison of the second event displays a similar level of consistence as with the first event. The very different sitesource distance of the Abeokuta and Kaduna earthquake means that significant record model would have surfaced with one of the events had the adopted attenuation parameters (the quality factor in particular) been not representative of real conditions of the wave travel path.

\subsection{Computed Synthetic Accelerograms}

Sample acceleration time-histories on "rock" conditions characteristics of some parts Nigeria are presented in Figures 2, 3 and $\mathbf{4}$ to show the increase in the duration of the accelerogram with earthquake magnitude and distance in accordance with the relationship defined in [31]. These accelerograms can be modified to represent the filtering effects of soil sediments using well-established standard procedures in which bedrock accelerograms are

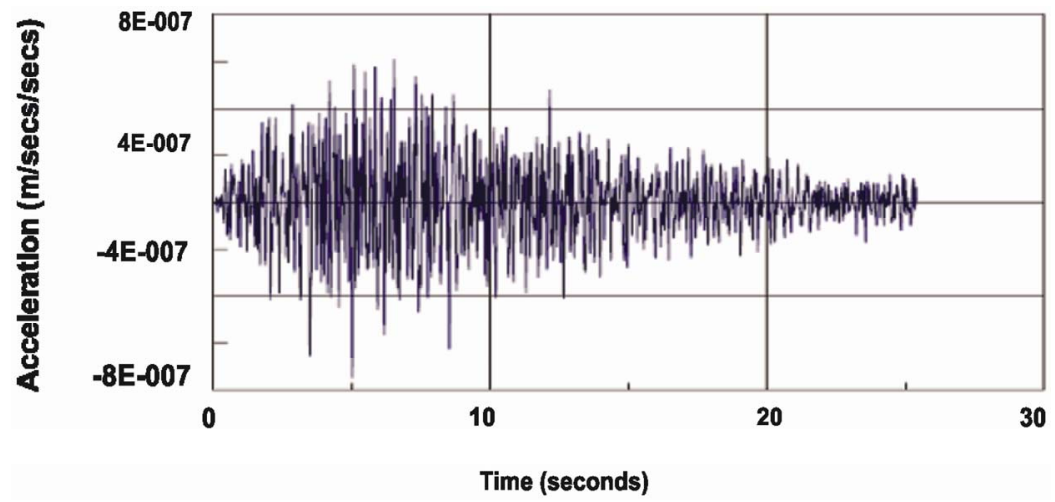

Figure 2. Time history of simulated accelerograms for earthquake scenario of $M>\mathbf{2 . 9}<\mathbf{5}$ for on rock characteristic of Ile-Ife, Southwestern Nigeria. 


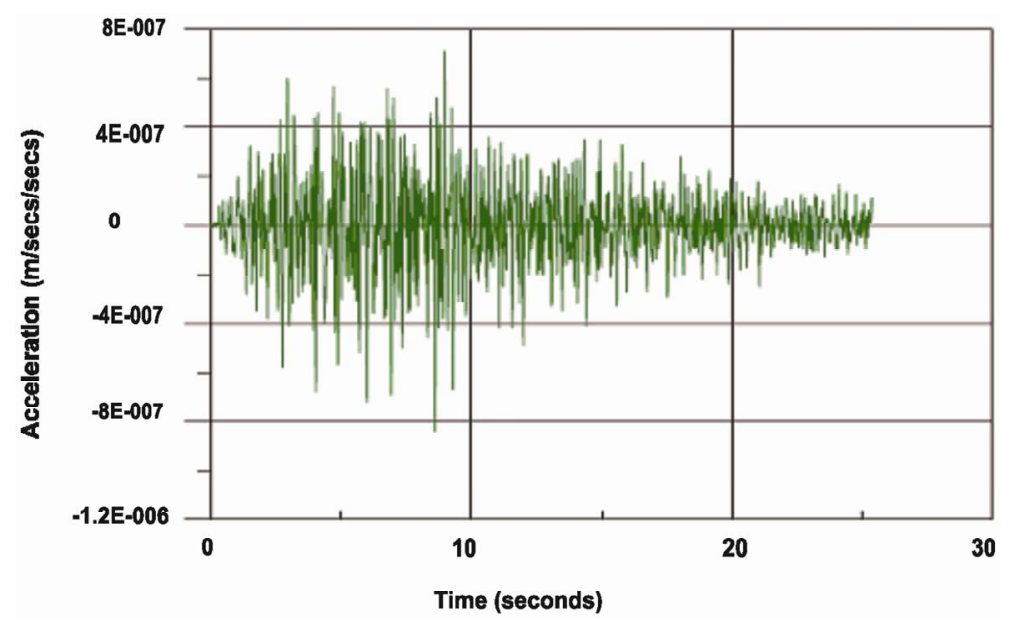

Figure 3. Time history of simulated accelerograms for earthquake scenario of $M>2.9<5, R=466 \mathrm{~km}$ on rock characteristic of Nsukka, Eastern Nigeria.

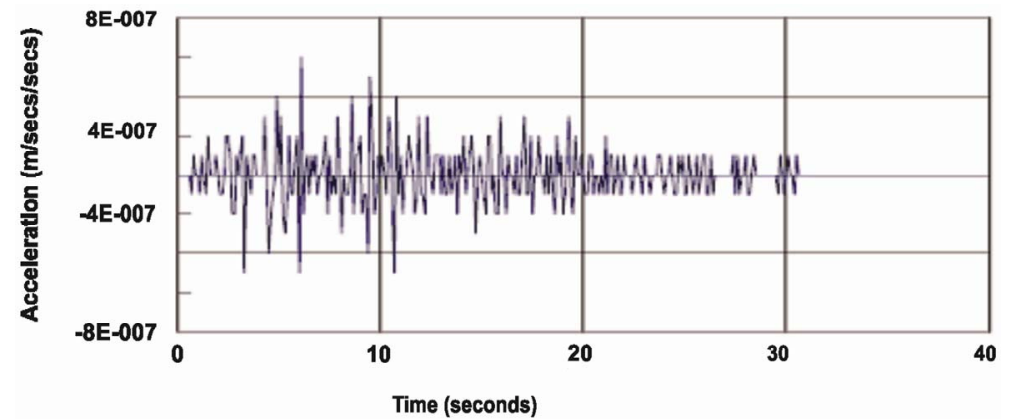

Figure 4. Time history of simulated accelerograms for earthquake scenario of $M>2.9<5, R=588 \mathrm{~km}$ on rock characteristic of Kaduna, Northern Nigeria.

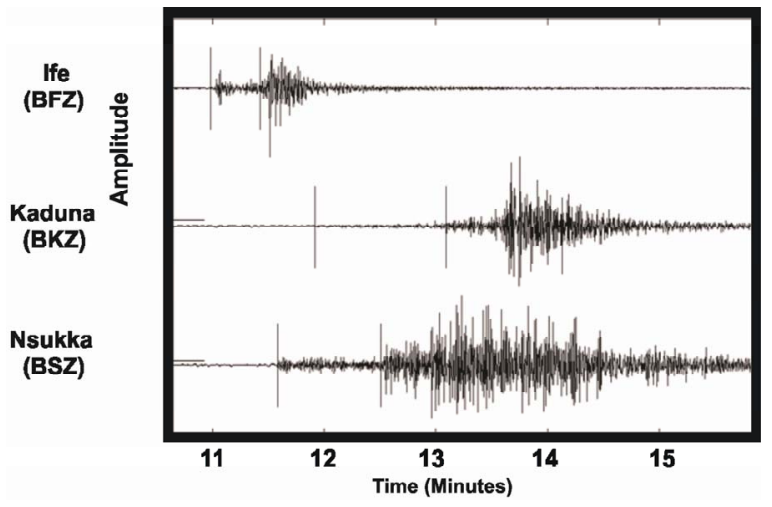

Figure 5. Earthquake seismogram recorded on September 11, 2009 for Ife, Kaduna and Nsukka seismic stations.

used as the input motion. Ground shaking could be significantly prolonged on soft soil sites (sedimentary regions) increasing the risk of damage to structures.

\section{Response Spectra}

Time History Analyses is considered to provide a more realistic representation of the actual response of the structure than Response Spectra Analyses (RSA) particularly when the response is characterized by non-linear (inelastic) behavior or significant torsional coupling behavior. When time-history analyses are performed in earthquake engineering studies, several representative ground motions should be used in order that the sensitivity of the response of the structure to random variations in the excitations can be deciphered. Large number of accelerograms representing a range of conditions was used in this study for multiple analyses is to be done.

Accelerograms that were recorded locally in Nigeria were typically taken from small magnitude events, aftershocks, or from long epicentral distances. Near-field motions of engineering significance are very difficult to capture due to the infrequent characteristics of intraplate earthquakes and also the insufficiency of strong ground motion data in Nigeria which does not meet seismic design requirements and earthquake studies. Strong motion accelerograms if recorded from outside Nigeria may misrepresent local conditions even though the records could be taken from regions that have low to moderate 
seismicity. The use of accelerograms generated artificially by computer based on stochastic simulations has become a viable alternative for THA. In this section, we intend to present the result of synthetic accelerograms that have been generated for engineering applications using program called GENQKE that was developed at the University of Melbourne [31-33] In view of the further occurrence of ground motion, our emphasis is on examining the peak ground velocity and response spectral properties of the accelerograms which is more useful in the engineering aspect. The simulation methodology used has been well established and review articles on this subject can be found in the literature [31].

It is shown that separate modelling is required for i) "hard rock" conditions and "rock" conditions of some regions in Nigeria. Response spectra of the generated accelerograms have also been calculated. Results were averaged and presented systematically for one magnitude and varying distances. The verification analyses also compared data collected from the $11^{\text {th }}$ of September 2009 Abeokuta earthquake against computer simulations. Results of the comparative analyses provide support to the claim that the generated accelerograms are generally consistent with local conditions as seen from Figure 5. Further verification analyses addressing the long-period behaviour of the accelerograms are presented in Figure 6. Response spectra for both rock and soft soil conditions are presented for comparison with the design response spectra are shown in Figure 7.

\subsection{Sensitivity Study on Sample Size}

Initially, the response spectrum of an individual simulated accelerogram was calculated. This response spectrum based on a single accelerogram was then compared with the average of six (6) accelerograms. Results of this comparative study are shown in Figures 2-5-for a

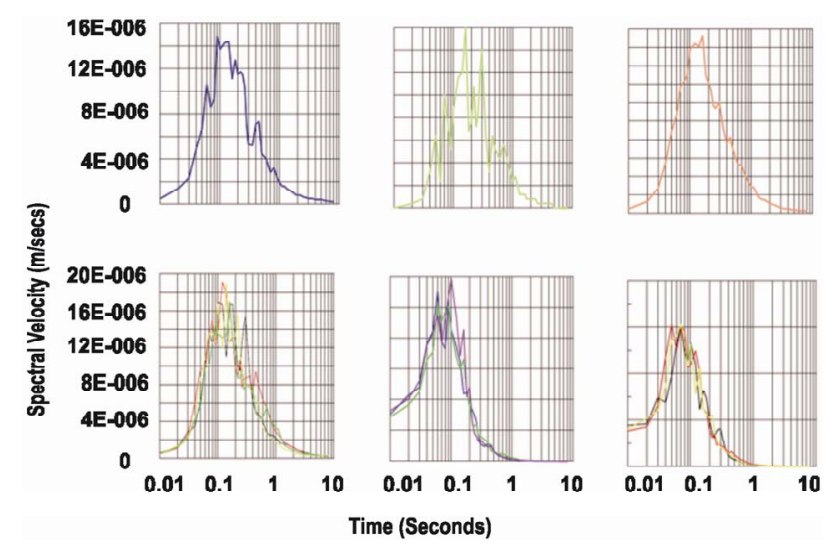

Figure 6. Sample size comparison of average response velocity and acceleration spectra.
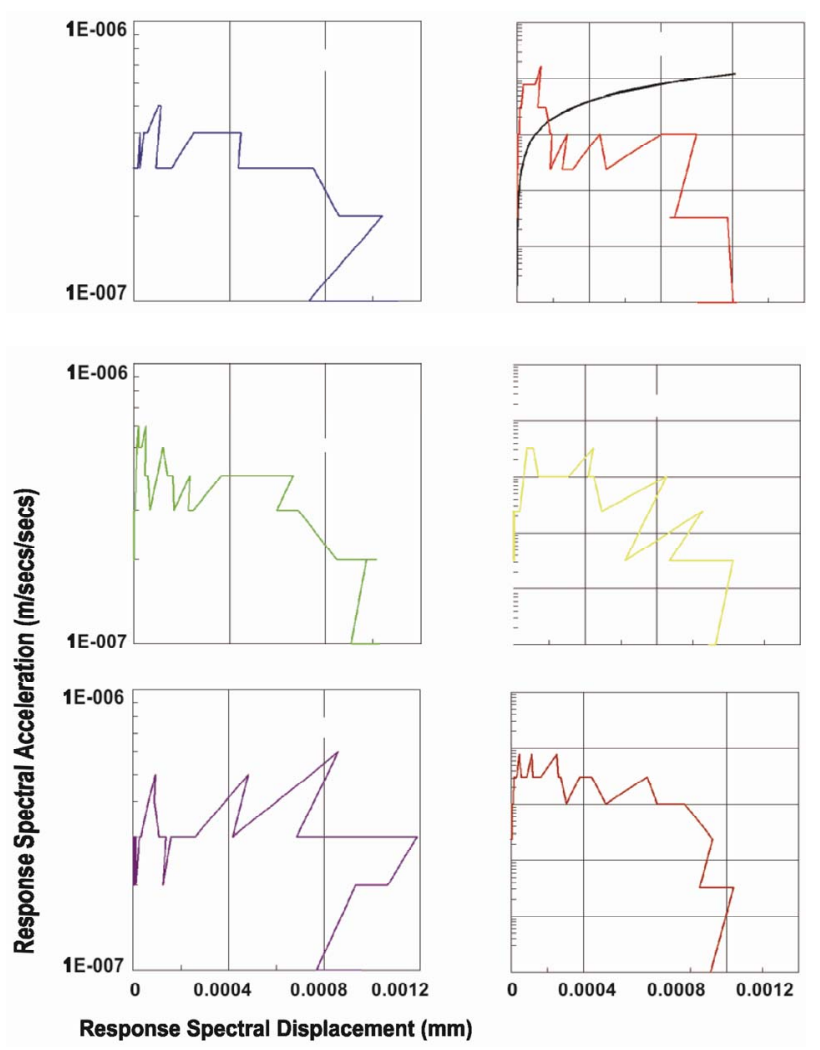

Figure 7. Displacement spectral Responses for the three Seismic stations. The left panels' show the results for Ife, Nsukka and Kaduna, while the right panel is the average displacement for the simulation for the three stations.

Magnitude $\mathrm{M}=4.8, \mathrm{R}=140 \mathrm{~km}$ earthquake. The irregular appearance of the response spectrum based on a single simulation is clearly noticeable, indicating a significant bias at certain periods. It is the opinion of the authors that a minimum of 4 - 6 randomly generated accelerograms has to be included in the analyses to effectively suppress the biases (as evidenced by the smoothness of the averaged response spectra associated with larger sample sizes).

\subsection{Response Spectra of Accelerograms Simulated}

Six random simulations have been produced for each earthquake scenario defined by a magnitude-distance (M-R) combination for the "rock" conditions of SouthWestern Nigeria. A response spectrum was then calculated for each simulation and results were averaged. A selection of the averaged response spectra is presented in Figure 6.

Estimation of this ground motion parameter either implicitly through the use of special earthquake codes or more specifically from site-specific investigations is es- 
sential for engineered structures. An important parameter used in earthquake engineering characterizing each response spectra is the notional peak ground velocity (PGV) which is defined herein as the highest point on the averaged velocity response spectrum divided by 1.8 . Thus, the peak ground acceleration estimated for the study area ranges from 0.16 to $0.69 \mathrm{~g}$, and the peak ground velocity from 18.0 to $58.3 \mathrm{~m} / \mathrm{sec}$ (Figures 6 and 7). The values presented as the peak ground acceleration (PGA) and peak ground velocity (PGV) are minute. Also, a good agreement has been found between computer simulations and field measurements [32].

Furthermore, spectral displacement is highly dependent upon seismic moment of the seismic shear wave whereas the spectra acceleration is mainly dependent on stress drop parameter of the earthquake ground motion and to a lesser extent on seismic moment. A particular threshold frequency called corner frequency is the frequency that dictates acceleration amplitude and in turn controls the frequency content of earthquake ground motion at the source. Thus the stress drop is believed to have contributed to high frequency content observed in intraplate earthquakes generally. This further confirms the information that displacement amplitude is controlled by low frequency while acceleration amplitude is controlled by high frequency. Stress drop of intraplate earthquakes is well correlated with very low slip rate of intraplate fault. Interestingly, observed stress drops did not show any significant difference between normal, reverse and strike-slip faulting system among intraplate earthquakes around the world.

The Abeokuta, Nigeria earthquake that occurred on the $11^{\text {th }}$ of September 2009 was deduced to be triggered of by the Romanche fracture zone. It is one of the largest offsets striking East-West that marks the Mid-Atlantic Ridge in the Atlantic Ocean. It is a normal fault with length of over $1000 \mathrm{~km}$, width of $200 \mathrm{~km}$, and occurs as a narrow break near the equator. We deduce that the seismic moment of the seismic shear wave of this earthquake ground motion possibly got attenuated in the sedimentary terrain of Nigeria. Displays of the displacement obtained are shown in Figure 7.

On the other hand, Figure 8 shows the attenuation plot for the seismic wave derived for the investigated area in Nigeria. A is simulated for a magnitude 3 earthquake, and $\mathrm{B}$ is for a magnitude 4.8 earthquake. The plot implies that there is moderate attenuation of the seismic waves in the study area. A general exponential decay of the curve is observed. This is in conformity with what is obtained around the world. We adjudged that the relation obtained from this study is the most plausible representation model that possibly corresponds to real ground motions for this affected area. It is well known that soils

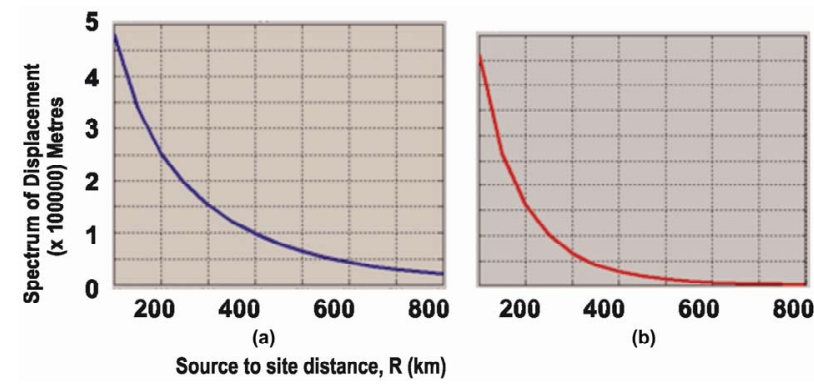

Figure 8. Attenuation plot for the seismic waves propagated on $11^{\text {th }}$ September 2009.

behave non-linearly when subjected to strong level of ground shaking. Soil site response function is not a single value for a specific site due to the soil having memory as it is dependent on soil damping and in turn related to the shaking level at crustal rock and overlying soil sediment interface.

From the resultant attenuation curves obtained from this study shown in Figure 8, it is pertinent to note that there is no obvious difference in the trend which is apparent among the different irrespective of the variation of the magnitude value. We envisaged that the decay curve accounts for damping effects of the soil which is very important in structural engineering for structural dynamic analyses. This is based on the fact that civil structures dissipate viscous energy on rock medium as a result of the damping effect. This decay is usually caused by the spherical spreading of the seismic shear waves generated by the earthquake at the Mohorovicic discontinuity and spherical spreading at the Gutenberg.

\subsection{Seismic Hazard Assessment}

The peak ground acceleration and velocity computed for the investigated area ranges from $(0.16-0.69) \mathrm{g}$ and $(18.0-58.3) \mathrm{m} / \mathrm{s}$, respectively. Using the peak ground values obtained and the amplifications computed from the numerical modeling, the investigated areas has been divided into three main hazard zones called low, moderate and high damage potential zones (Figure 9). The estimated PGA and PGV values obtained from this study were used in deriving the seismic hazard map for the study area. The seismic ground motion of Nigeria has been computed, and the hazard zones assessed based on the computations from synthetic accelerograms that take simultaneously into account the source, path and site effects. The parameters obtained from the accelerograms and response spectra allow us to estimate the seismic hazard of some parts of Nigeria.

Areas underlain by unconsolidated sediments (having low mechanical strength) are classified as the maximum 

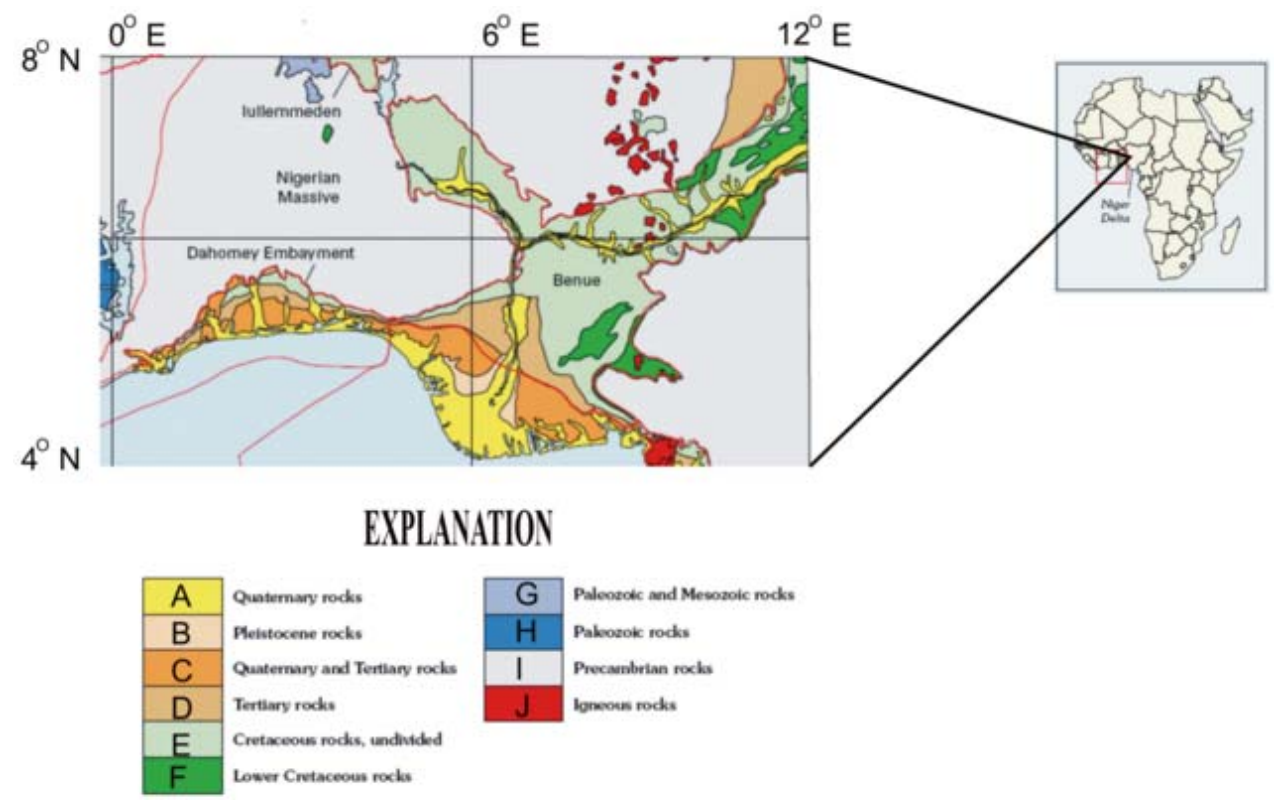

EARTHQUAKE DAMAGE CLASSIFICATION

\section{A - F MAXIMUM DAMAGE POTENTIAL}

\section{G - H MODERATE DAMAGE POTENTIAL}

\section{I - J LOW DAMAGE POTENTIAL}

Figure 9. Seismic hazard map of some parts of Nigeria derived from the PGA and PGV values obtained in this study.

damage potential zone. The presence of low velocity sediments possibly contributed to the high peak values and amplifications obtained. Whilst those underlain by meta-sediments are said to be the moderate damage potential zone, and highly consolidated geological formation, that is, areas having very high mechanical properties) are classified as low damage potential zone. Buildings in these areas classified as the maximum damage potential zone, and should be designed to resist such high ground acceleration. As development within the metropolis is generally not controlled or planned, it makes the area a recipe for major disaster in the event of a strong earthquake. Buildings are poorly designed and constructed and the building codes are not adhered to strictly.

It is inferred that areas that lies within the moderate to high damage potential zones are more likely susceptible to severe damage if another ground movement having high PGA values should occur, it is envisaged that structures and buildings would be destroyed with loss of lives and property when an earthquake of such intensity strikes the area. The maximum peak ground acceleration estimated is located in areas denoted as zones with low velocity geological formations such as continental and marine deposits in the especially the low-lying coastal regions where a lot of and local construction practices are in progress. Also, areas characterized by highly consolidated geological materials are classified as low damage potential zones are the areas that will be least affected by any earthquake or tremor.

The results of the numerical simulation have been extended to all other areas with similar geological formation. It is now possible to define realistic seismic parameters for the already built area. Damage in such heavily populated area. The ground motion parameters obtained is useful for urban planning, retrofitting of the built environment, for earthquake preparedness and risk reduction. Civil Engineers can use the parameters as seismic input for the design of structures in future construction works of civil structures. This is a prerequisite to curtail the negative impact of any strong earthquake on structures in the investigated areas.

\section{Conclusions}

Nigeria is known to be on a stable part of the African 
shield, and a reliable assessment of seismic risk in this region requires knowledge and understanding of both the seismicity and the attenuation of strong ground motion. The seismic ground motion of the south-western Nigeria has been computed using stochastic modelling technique and the hazard zones assessed. The results obtained were correlated with field events recorded on $11^{\text {th }}$ September 2009. A good correlation between the two was obtained. This showed that stochastic modelling could be effectively used as a predictive tool both for the basement complex and sedimentary terrain of Nigeria. The peak ground acceleration estimated for the study area ranges from 0.16 to $0.69 \mathrm{~g}$, and the peak ground velocity from 18.0 to $58.3 \mathrm{~m} / \mathrm{sec}$. These correspond to intensity ranging from VII to IX on the MM Intensity scale of Bolt (2004). The high peak values of accelerations and amplifications delineated are possibly due to the presence of the low velocity sediments. Also, the resultant spectra attenuation curves generated synthetically across three (3) different stations with a distance of $466 \mathrm{~km}$ (Nsukka) and $588 \mathrm{~km}$ from Ile-Ife represent typical spectral for the basement complex and sedimentary terrains. It is concluded that the differences between the three (3) curve types obtained for the three cities showed that distance is a more important factor than magnitude in determining the shape of spectra attenuation. We observe that the maximum peak ground acceleration is located in areas having low velocity layers. In terms of seismic vulnerability, the investigated area is classified into maximum (sedimentary), moderate (meta-sediments) and low damage potential (basement rocks). Therefore, buildings in these areas should be designed to resist such high ground acceleration. The seismic ground motion parameters computed is useful to future urban planning development and structural design.

\section{Acknowledgements}

The Third World Academy of science is appreciated for the research grant that enabled us carry out this research. Also, the research grant support (11801BOW) of the University Research Council at Obafemi Awolowo University, Ile-Ife, Nigeria is acknowledged. Also, the Center for Geodesy and Geodynamics and Geodesy (CGG), Toro, Bauchi State Nigeria appreciated for the technical assistance.

\section{References}

[1] I. A. Beresnev and G. M. Atkinson, "Modelling Finite-Fault Radiation from the Spectrum," Bulletin of the Seismological Society of America, Vol. 87, No. 1, 1997, pp. 67-84.
[2] N. M. Newmark and W. J. Hall, "Earthquake Spectra and Design," Earthquake Engineering Research Institute Monograph Series, 1982.

[3] M. E. Omatsola and O. S. Adegoke, "Tectonic Evolution and Cretaceous Stratigraphy of the Dahomey Basin," Journal of Mining and Geology, Vol. 18, No. 1, 1981, pp. 130-137.

[4] N. G. Obaje, "Geology and Mineral Resources of Nigeria," In S. Bhattacharji, et al., Eds., Lecture Notes in Earth Sciences, Springer-Verlag, Berlin, 2009, pp. 1-219.

[5] M. A. Rahaman and O. O. Ocan, "On Relationship in the Precambrian Migmatite Gneiss of Nigeria," Journal of Mining and Geology, Vol. 15, 1978, pp. 23-30.

[6] C. Barnaba, E. Priolo, A. Vuan and M. Romanelli, "Site Effect on the Strong Motion Site at Tolmezzo-Ambiesta Dam in Northeastern Italy," Bulletin of the Seismological Society of America, Vol. 97, No. 1B, 2007, pp. 339-346. doi:10.1785/0120060077

[7] S. Drouet, S. Chevrot, F. Cotton and A. Souriau, "Simultaneous Inversion of Source Spectra, Attenuation Parameters, and Site Responses: Application to the Data of the French Accelerometric Network," Bulletin of the Seismological Society of America, Vol. 98, No. 1, 2008, pp. 198-219. doi:10.1785/0120060215

[8] N. Lam, C. Sinadinovski, R. Koo and J. Wilson, "Peak Ground Velocity Modelling for Australian Intraplate Earthquake," Journal of Earthquake Engineering \& Structural Dynamics, Vol. 5, No. 2, 2003, pp. 11-22.

[9] H. H. Tsang, N. T. K. Lam and S. H. Lo, "Site-Dependent Response Spectral Attenuation Modelling: A Case Study of Long Distance Earthquakes Affecting Singapore," International Journal of Geology, Vol. 1, No. 1, 2007, pp. 6-10.

[10] L. Malagnini, K. Mayeda, R. Uhrhammer, A. Akinci and B. R. Herrmann, "A Regional Ground-Motion Excitation/Attenuation Model for the San Francisco Region," Bulletin of the Seismological Society of America, Vol. 97, No. 3, 2007, pp. 843-862. doi:10.1785/0120060101

[11] T. I. Allen and D. J. Wald, "Evaluation of Ground-Motion Modeling Techniques for Use in Global ShakeMap-A Critique of Instrumental Ground-Motion Prediction Equations, Peak Ground Motion to Macroseismic Intensity Conversions, and Macroseismic Intensity Predictions in Different Tectonic Settings," US Geological Survey Open-File Report 2009-1047, 2009, p. 114.

[12] J. Douglas, "On the Regional Dependence of Earthquake Response Spectra," ISET Journal of Earthquake Technology, Vol. 44, No. 1, 2007, pp. 77-99.

[13] J. Douglas, "Investigating Possible Regional Dependence in Strong Ground Motions," Earthquake Data in Engineering Seismology, Vol. 14, Part 1, 2011, pp. 29-38.

[14] J. Zhang and C. Yang, "Characteristics of Seismic Responses at Liquefied and Non-Liquefied Sites with Same Site Conditions," Journal of Modern Transportation, Vol. 19, No. 2, 2011, pp. 134-142.

[15] E. H. Vanmarcke, "Seismic Risk and Engineering Decisions, Chapter 8," Elsevier Publishing Co., New York, 
1977.

[16] R. K. McGuire, "A Simple Model for Estimating Fourier Amplitude Spectra of Horizontal Ground Acceleration," Bulletin of the Seismological Society of America, Vol. 68, No. 3, 1978, pp. 803-822.

[17] M. D. Trifunac, "Dependence of Fourier Spectrum Amplitudes of Recorded Earthquake Accelerations on Magnitude, Local Soil Conditions and on Depth of Sediments," Earthquake Engineering Structure Dynamics, Vol. 18, No. 7, 1989, pp. 999-1016. doi: $10.1002 /$ eqe. 4290180706

[18] G. Gibson, "Artificial Ground Motions," Proceedings of a Seminar Held by the Australian Earthquake Engineering Society of The Institute for Engineers Australia, Melbourne, 1993, pp. 83-86

[19] K. W. Campbell, "The Dependence of Peak Horizontal Acceleration on Magnitude, Distance, and Site Effects for Small-Magnitude Earthquakes in California and Eastern North America," Bulletin of the Seismological Society of America, Vol. 79, No. 5, 1989, pp. 1311-1346

[20] G. M. Atkinson and D. M. Boore, "Ground Motion Relations for Eastern North America," Bulletin of the Seismological Society of America, Vol. 85, 1995, pp. 17-30.

[21] J. N. Brune, "Tectonic Stress and the Spectra of Seismic Shear Waves from Earthquakes," Journal of Geophysical Research, Vol. 75, No. 26, 1970, pp. 4997-5009.

[22] D. M. Boore, "Stochastic Simulation of High-Frequency Ground Motions Based on Seismological Model of the Radiated Spectra," Bulletin of the Seismological Society of America, Vol. 73, No. 6, 1983, pp. 1865-1894.

[23] D. M. Boore and G. Atkinson, "Stochastic Prediction of Ground Motion and Spectral Response Parameters at Hard-Rock Sites in Eastern North America," Bulletin of the Seismological Society of America, Vol. 73, 1987, pp. 1865-1894.

[24] T. C. Hanks and R. K. McGuire, "The Character of High-Frequency Strong Ground Motion," Bulletin of the Seismological Society of America, Vol. 71. No. 6, 1981, pp. 2071-2095.

[25] G. Atkinson and W. Silva, "An Empirical Study of Earthquake Source Spectra for Californian Earthquakes," Bul- letin of the Seismological Society of America, Vol. 87, No. 1, 1997, 97-113.

[26] I. A. Beresnev and G. M. Atkinson, "Source Parameter of Earthquakes in Eastern and Western North America Based on Finite-Fault Modelling," Bulletin Seismological Society of America, Vol. 92, No. 2, 2002, pp. 695-710. doi: $10.1785 / 0120010101$

[27] G. Atkinson and P. Somerville, "Calibration of Time History Simulation Methods," Bulletin of the Seismological Society of America, Vol. 84, 1994, pp. 400-414.

[28] A. M. Chandler, N. T. K. Lam and H. H. Tsang "Regional and Local Factors in Attenuation Modelling: Hong Kong Case Study," Journal of Asian Earth Sciences, Vol. 27 , No. 6, 2006, pp. 892-906. doi:10.1016/j.jseaes.2005.09.005

[29] G. M. Atkinson and D. M. Boore, "Evaluation of Models for Earthquake Source Spectra in Eastern North America," Bulletin of the Seismological Society of America, Vol. 88, 1998, pp. 917-934

[30] CRUST2.0, Institute of Geophysics and Planetary Physics, University of California, San Diego, 2001. http://mahi.ucsd.edu/Gabi/rem.dir/crust/crust2.html

[31] N. T. K. Lam, J. L. Wilson and G. L. Hutchinson, “Generation of Synthetic Earthquake Accelerograms Using Seismological Modelling: A Review," Journal of Earthquake Engineering, Vol. 4, No. 3, 2000, pp. 321-354. doi:10.1080/13632460009350374

[32] N. T. K. Lam, J. L. Wilson, A. M. Chandler and G. L. Hutchinson, "Response Spectral Relationships for Rock Sites Derived from the Component Attenuation Model," Earthquake Engineering and Structural Dynamics, Vol. 29 , No. 10, 2000, pp. 1457-1489. doi:10.1002/1096-9845(200010)29:10<1457::AID-EQE9 69>3.0.CO;2-Q

[33] N. T. K. Lam, J. L. Wilson, A. M. Chandler and G. L. Hutchinson, "Response Spectrum Modelling for Rock Sites in Low and Moderate Seismicity Regions Combining Velocity, Displacement and Acceleration Predictions," Earthquake Engineering and Structural Dynamics, Vol. 29, No. 10, 2000, pp. 1491-1526. doi:10.1002/1096-9845(200010)29:10<1491::AID-EQE9 70>3.0.CO;2-T 